\title{
Timescapes of Community Resilience and Vulnerability in the Circumpolar North
}

\author{
MARTIN ROBARDS ${ }^{1,2}$ and LILIAN ALESSA ${ }^{1}$
}

\author{
(Received 13 January 2003; accepted in revised form 16 October 2003)
}

\begin{abstract}
Historical relationships between people and a changing Arctic environment (which constitute a social-ecological system, or SES) can offer insights for management that promote both social and ecological resilience. The continued existence of healthy renewable resources around communities is particularly important, as subsistence and commercial use of local resources are often the only practical avenues to healthy, long-term security for those communities. Our research draws on the position that SESs exist in an environment that is explicitly temporal: frequently cyclic, changing, contextual, and contingent. Therefore, the causes and effect of disturbances to SESs are rarely temporally linear; instead, they are characterized by a complex array of hysteretic effects and alternate (possibly repeating) states. The term 'timescapes' describes the time-space context element and its fundamental importance to sustainable practices. We investigate social-ecological timescapes of the circumpolar North in relation to four primary provisioning practices (hunting/gathering, pastoralism, agriculture, and market-based economy). Broadly, we identify distinct social-ecological states, interspersed with periods of change. For specific communities that have maintained their existence through a series of periods of profound change, we propose that elements of social and ecological resilience have been neither incrementally lost nor gained through time; rather, they have waxed and waned in accordance with specific, and sometimes repeating, conditions. To maintain their existence, we believe, communities have had to maintain their ability to recognize gradual or rapid changes in social, ecological, or economic conditions and reorganize themselves to adapt to those changes, rather than to any specific outcomes of a change. That is, they have adapted to a dynamic environment, not a preferred state. However, centralized Western management, despite fundamental flaws in accounting for local linkages between culture, economics, and the environment, is increasingly circumscribing local practices. We believe that the significant challenge of maintaining equity and resilience of remote communities, within and outside the Arctic, will necessitate incorporating localized cultural values and decision-making processes that fostered prior community existence with (data from) Western interdisciplinary research.
\end{abstract}

Key words: circumpolar north, timescapes, resilience, vulnerability, provisioning, social-ecological systems

RÉSUMÉ. Les relations historiques entre les êtres humains et un milieu arctique en évolution (formant un système socioécologique ou SSE) peuvent nous éclairer sur une gestion qui appuie à la fois la résilience sociale et la résilience écologique. La présence continue de ressources renouvelables saines dans les environs des collectivités est d'une importance capitale, vu que l'utilisation des ressources locales à des fins de subsistance et de commerce représente souvent le seul moyen concret d'assurer la santé à long terme de ces collectivités. Nos travaux partent du principe que les SSE existent dans un milieu qui est explicitement temporel: fréquemment cyclique, changeant, dépendant du contexte et contingent. Il en ressort que les causes et les conséquences des perturbations aux SSE sont rarement linéaires dans le temps, mais plutôt caractérisées par un ensemble complexe d'effets d'hystérésis et d'états alternatifs (se répétant éventuellement). L'expression «échelle de temps et d'espace» décrit l'élément du contexte spatio-temporel et son importance fondamentale pour les pratiques durables. On étudie les échelles de temps et d'espace socio-écologiques du Nord circumpolaire en rapport avec quatre pratiques primaires d'approvisionnement (chasse / cueillette, pastoralisme, agriculture et économie de marché). D’une façon générale, on dégage des phases socio-écologiques distinctes, séparées par des périodes de changement. Pour certaines collectivités qui ont survécu durant une série de périodes de changements profonds, on suggère que les éléments formant la résilience sociale et écologique n' ont pas disparu, pas plus qu'ils n'ont été acquis de façon progressive au cours du temps; ils ont plutôt fluctué selon des conditions spécifiques, qui se répétaient parfois. Afin de se perpétuer, selon nous, ces collectivités ont dû maintenir leur capacité à reconnaître les changements graduels ou rapides qui se manifestaient dans les conditions sociales, écologiques ou économiques, et se réorganiser elles-mêmes pour s'adapter à ces changements, plutôt qu'à des conséquences spécifiques issues des changements. Ce qui revient à dire que ces collectivités se sont adaptées à un environnement dynamique, et non à un état qu'elles privilégiaient. Cependant, bien qu'elle comporte des failles fondamentales concernant la reconnaissance des liens de nature locale entre culture, économie et environnement, la gestion occidentale centralisée limite de plus en plus les pratiques locales. On est d'avis que le grand défi pour maintenir l'équité et la résilience des collectivités isolées, dans l'Arctique et à l'extérieur, exigera que l'on intègre les valeurs de la culture locale et les processus décisionnels qui ont soutenu l'existence antérieure de la collectivité aux données de recherche interdisciplinaire occidentale.

\footnotetext{
${ }^{1}$ Biological Sciences, University of Alaska, Anchorage, 3211 Providence Drive, Anchorage, Alaska 99508, U.S.A.

${ }^{2}$ Corresponding author: ftmdr@uaf.edu

(C) The Arctic Institute of North America
} 
Mots clés: Nord circumpolaire, échelles de temps et d'espace, résilience, vulnérabilité, approvisionnement, systèmes socioécologiques

Traduit pour la revue Arctic par Nésida Loyer.

\section{INTRODUCTION}

While humans have been responding to and affecting the biophysical system for millennia (Smith and Wishnie, 2000; CAFF, 2001), our contemporary understanding of both the complex feedbacks by which humans perceive, use, and alter the environment and the scale dynamics (temporal and spatial) of these activities is still limited. As a consequence, current Western management regimes and predictive models are inherently flawed, which severely limits their application and power, particularly at local scales, where most models do not apply. Accordingly, persistent, sometimes swift, and well-documented switches to alternative, less healthy and diverse, ecosystem states continue to occur in concert with human population growth, globalization, technology advances, and changing social norms (e.g., McGoodwin, 1990; Freese, 2000; Jackson et al., 2001; Scheffer et al., 2001; Folke et al., 2002). In the struggle to find effective solutions, there has been increasing scrutiny of the entrenched nature/culture dualism that separates academic disciplines (e.g., ecology from sociology), as well as of the management frameworks that interface with communities. The status-quo dualism does not permit us to elucidate, either in concept or in application, the direct or indirect feedbacks that create socialecological systems, particularly in the Arctic, where communities maintain close connections with the natural environment and are less influenced by urbanization.

Deeper understanding of the complex linkages and feedbacks that exist as fast or slow processes within socialecological systems is clearly vital to the wise implementation of effective management policies, including those that promote social and ecological resilience (Holling, 1986; Berkes and Folke, 2001; Folke et al., 2002) and sustainability (Costanza, 1996; Holling, 2001; Newton et al., 2002). Resilience is the potential of a social-ecological system to remain in a particular configuration, maintaining its feedbacks and functions following disturbance and stresses, or involves the ability of that system to reorganize into an alternative but functional state following profound, disturbance-driven change. We interpret vulnerability as the antonym of resilience. In contrast, sustainability is an overarching goal that generally includes human assumptions or preferences about specific social-ecological characteristics that are deemed desirable (Walker et al., 2002). Sustainability may also be regarded as the challenge to avoid crossing irreversible thresholds that damage ecological function, while creating long-term economic, political, and moral arrangements that secure the well-being of present and future generations (Orr, 2002).
Without coherent epistemologies of how social-ecological systems function, Western policy and management have often relied on culturally biased techno-managerial remedies (Goldman and Schurman, 2000) in attempts to rectify frequently rapid breakdowns in SES function. This approach draws on Western hubris: it assumes that advances in technology and centralized control can solve environmental problems. These remedies are generally preferred (and constituted) by discipline-restricted, Western policymakers in the (often futile) attempt to stabilize ecosystem outputs and sustain consumption patterns (Holling and Meffe, 1996; Haila, 1999; Carpenter and Gunderson, 2001). Recognizing that unpredictable triggers of social-ecological change will continue to occur, effective natural resource management will more likely require proactive, precautionary measures, rather than reactive responses to the often rapid changes in social or ecosystem functions. It has been argued that such preventative action can only occur through the identification and respect of critical ecological thresholds and the use of management that is adaptive, reflexive, and sensitive to local peculiarities (Haila, 1999). By extension, such management requires the social flexibility (or adaptive capacity, see Walker et al., 2002) to learn, cope, innovate, and adapt to change (Holling, 2001), rather than to any specific outcomes of change. We expect that solutions defined, modified, and administered by the community will be required: solutions that promote community resilience and reflect the appropriate scale and past experience of a particular SES.

Indigenous human societies across the globe have developed rich sets of experience and holistic explanations relating to the environments they live in (Nakashima et al., 2000). In the harsh and often marginal environment of the circumpolar North, people have often coped successfully over millennia, while developing extensive knowledge and keen awareness of ecosystem changes (Schlosser et al., 1998). Consequently, the longevity of many Arctic cultures has been facilitated by adaptive responses such as migrations, rapid subsistence shifts, the development of new technologies, new economic practices, ecological manipulation, and other social and cultural transitions (Berkes and Folke, 2001; CAFF, 2001). Since culture may be defined as the way a human group adapts to its environment (economic or ecological), the environment is embedded in and perceived through cultural traditions; in other words, cultural norms embody place-specific memory of change, feedbacks, and repercussions. Therefore, cultural norms that persist in resource-dependent communities might be expected to reflect actions that have mitigated the effects of persistent change (rather than trying to prevent 
change) by fostering resilience. The evolutionary pressure for creating, accumulating, and transmitting (Berkes and Folke, 2001) the cultural norms that fostered survival of indigenous cultures is presumably strong in the Arctic environment. At low population levels, cultural norms in subsistence-based communities are also likely to represent specific survival parameters that developed from more basic instinctive human responses, although survival parameters clearly did not always overcome environmental change and exploitation.

Thus a retrospective investigation of cultural values, understanding, perception, and behaviors of specific northern communities in relation to resource provisioning practices (including those that result from regionalization), if conducted with an appreciation of the survival attributes embedded in cultural norms, should shed light on the relevance of the values, understanding, perception, and behaviors to the resilience and sustainability (cultural, ecological, and economic) of those communities. Naturally evolved choices would have to deal with, and specifically mitigate, the challenges posed by "impairment" (increased social-ecological system vulnerability through loss of resilience) and uncertainty, favoring decisions that balance the risks associated with biophysical functionality against those of social, cultural, and economic disruption. At the circumpolar scale, we see a range of culturally organized relationships between people and natural resources (social-ecological system or cultural landscapes; Stoffle, 2001). By adding a temporal component, we expect to elucidate the cyclic (e.g., seasonal), changing, contextual (e.g., transportation, geography, and institutions), and contingent dynamics of the cause and effect of disturbances to natural and cultural components of SESs. Responses to disturbances in SESs are rarely temporally linear; they are characterized by hysteretic effects and alternate (possibly repeating) states - in contrast to traditional linear ecological notions such as climax with an end-point (Berkes and Folke, 2001). Thus, as Adam (1998:10) stated, "We are dealing with phenomena where the impacts of actions work invisibly below the surface until they materialize as symptoms-some time, somewhere" producing a potentially parasitic relationship between current and future generations. The timescape in Figure 1 shows fast (dotted line) and slow (solid line) responses to a disturbance (social, ecological, economic, or a combination of these) portrayed as intensity of effect. The timescape includes the full period required to observe all effects within a system (e.g., effects on social, ecological, and economic processes). For example, an extractive industry may produce short-term economic growth that lasts less than one human generation, but the population increase associated with this new wealth may appear significantly later than the directly tangible effects. Any time lag between the start of effects and the observation of those effects (shown by the horizontal line between ascent and descent of intensity curve) compounds the hysteretic nature of cause and effect. A timescape approach illustrates that vulnerability to change will include components of as yet unmanifested phenomena associated with temporally divergent disturbances. Only by recognizing the full temporal dynamic of disturbances - the timescape-can wise and just management decisions be made. We expect that many cultural parameters that fostered social and ecological resilience in the past will incorporate timescape considerations and therefore be just as relevant today, though the integration of technology and globalization will have altered the types of components manifested.

We emphasize that our research does not attempt to impute conservationist purposes to indigenous practices just because they seem analogous to modern management practices. Furthermore, we agree that the future cannot be managed purely on the basis of past experience (Adam, 1998). We do not, therefore, describe which historical practices might be sustainable or promote resilience now. Our objective is to increase our temporal understanding of how resilience varies under different local provisioning scenarios. We will describe which cultural, social, and ecological conditions favor the fostering of linked socialecological resilience in remote, resource-dependent communities and which conditions favor destruction of resilience, or overexploitation of local resources. Many Arctic communities are small and vulnerable because of isolation (both geographical and economic), high unemployment, and susceptibility to climate change (Young, 1992; Berardi, 1998; McTiernan, 1999; Krupnik and Jolly, 2002). Furthermore, many of these communities have and will continue to require ecosystem services (such as subsistence resources) for their practical and cultural existence (e.g., Ziker, 1999). Therefore, identifying critical SES components that drive change and using this knowledge to promote community resilience in the face of changing circumstances (Andersen et al., 2002) are of great value (Smith and Wishnie, 2000; Berkes and Folke, 2001; Freeman, 2001), particularly to the communities themselves.

\section{CONCEPTUAL FRAMEWORK}

Ecologically sustainable development for resourcedependent communities requires equity between the functional dimensions of ecology, sociology, cognition, and economic aspects of resource use (Beckley et al., 2002; Deutsch et al., 2003) to meet current needs without compromising the ability of future generations to meet their own needs (WCED, 1987). Since sustainability requires the maintenance of resilience in one time period or at a particular scale, without causing erosion to resilience in a latter period or at another scale (Carpenter et al., 2001), long-term, cross-timescape analysis is required to ascertain implications from the interconnectedness of different social-ecological strategies. We hypothesize that though many indigenous Arctic communities have changed demographically (i.e., there is no longer a strict dichotomy 


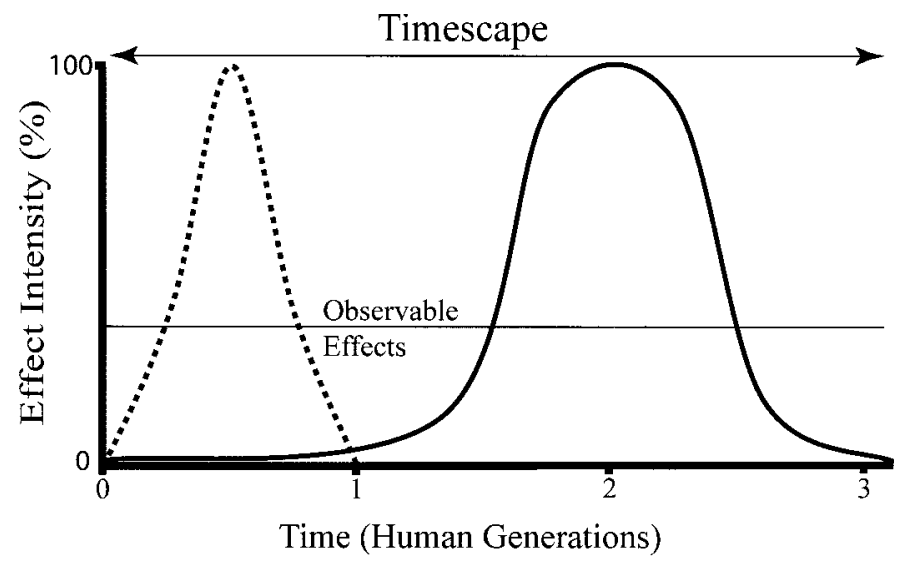

FIG. 1. Timescape graphical representation of fast (dotted curve) and slow (solid curve) responses to a disturbance (either social, ecological, economic, or a combination), portrayed as intensity of effect.

between indigenous and Western cultures) and in their primary provisioning practices (from a strictly hunter/ gatherer subsistence lifestyle to one that operates in a mixed market and local-harvest economy), the basic need for social-ecological resilience has not changed. Furthermore, we emphasize that the application of resilience is not restricted to Arctic communities. To support our hypothesis, we explore the four primary resource-provisioning practices (hunting/gathering, pastoralism, agriculture, and market-based provisioning) within circumpolar North SESs to show the value of timescape models to illuminate cultural and biophysical changes and attendant feedbacks on both spatial and temporal scales. Our goal is to illuminate linked social-ecological components of resilience that have implications for a community's ability to change and adapt to new circumstances as they occur.

Figure 2 shows our conceptual model for exploring timescapes. We expect that the biophysical environment and outside influences (immigration, regionalization, and globalization) shape local culture. The way a specific local culture supports itself through hunting/gathering, pastoralism, agriculture, or a market-economy is represented proportionally within the composite kite diagram representing a social-ecological relationship. We expect that inherently resilient relationships will often be characterized by their longevity. Conversely loss of resilience would be seen as switching to alternative, and possibly less desirable, relationships. Of particular interest are feedbacks that link back from a specific timescape of harvest practices to the biophysical environment. These feedbacks may be synergistic or antagonistic to resilience or sustainability or both. Along with changing external influences, they may provide enough momentum to cause cultural changes in harvest practices that lead to alternate relationships. Adaptive capacity is the ability of a community to maintain a livelihood within the matrix represented by the kite diagram, while avoiding overcapacity, collapse, or minimizing of future options in the event of change. Scarcity of resources forces communities toward a market-based economy. Conversely, scarcity of monetary

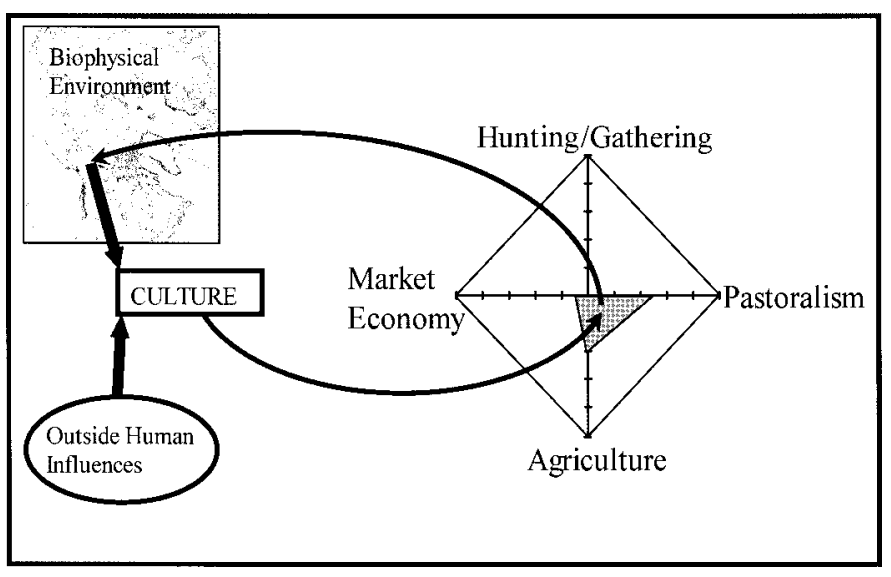

FIG. 2. Conceptual model for exploring timescapes.

means forces communities toward subsistence. Lack of components for reorganization into alternate, but viable community provisioning states may lead to collapse.

The vulnerability, or tendency to suffer harm from exposure to external stresses and shocks, of a specific community (manifested through combinations of social, ecological, or economic vulnerability) to a forcer of change (e.g., climate or economic) at a specific time has been described as:

$$
V u l=f(\operatorname{Exp}, A d C a p) \quad \text { Model } 1
$$

where $V u l$ is the vulnerability of a community, Exp is the exposure to a perturbation, and AdCap is a community's capacity to adapt to that change (e.g., Smit and Pilifosova, 2001). However, Model 1 does not implicitly recognize the complex temporal interplay between sequential exposures to perturbations and adaptive capacity. The resilience of a resource-dependent community is a function of its ability to adapt continually to ever-changing conditions-seasonal, annual, decadal, and centennial-irrespective of the natural or anthropogenic origin of the causative factors, without depreciating opportunities of future generations. Furthermore, sequential perturbations from multiple sources affecting any combination of social, ecological, or economic systems can lead to sequential impairment unless adaptive capacity (in each system element) regenerates as fast, or faster, than it is eroded. Figure 3 conceptually illustrates the effects on resilience from sequential perturbations to these systems. If adaptive capacity is not recovered after perturbations, cumulative loss of resilience can occur. Conversely, if communities can adapt fully to sequential changes, mitigating the perturbation while maintaining or improving their adaptive capacity, they will likely be more resilient to future disturbances. We emphasize that adaptive capacity may be sequentially impaired by any combination of perturbations and the management responses to those perturbations. Management designed to maximize adaptive capacity, rather than to maximize or stabilize yields of temporally variable resources, promises greater resilience during periods of profound change. 


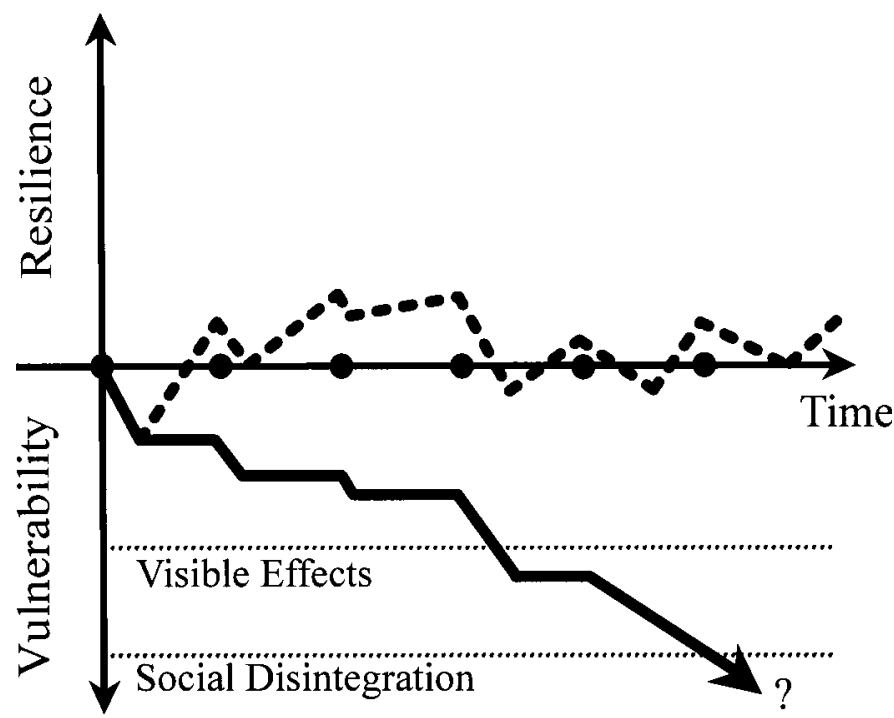

FIG. 3. Conceptual illustration of effects on resilience from sequential perturbations to social, ecological, or economic systems (indicated as solid circles on $\mathrm{x}$-axis). Cumulative loss of resilience can occur in systems where adaptive capacity is not recovered after perturbations (solid line). In contrast, resilience might be maintained with attention to recovering adaptive capacity between perturbations (dotted line)

We therefore propose Model 2, which better recognizes the contextual and dynamic nature of adaptive capacity in a changing social-ecological environment and the fact that adaptive capacity is contingent on all hysteretic effects of prior perturbations, including those yet to be manifested:

$$
\frac{d V u l}{d t}=f\left(\sum \operatorname{Exp}_{(F+L+S)} \frac{d A d C a p}{d t}\right) \quad \text { Model } 2
$$

where $\operatorname{Exp}_{(F+L+S)}$ is the frequency, longevity, and spatial extent of a perturbation. In this model the rate of change of vulnerability is a function of the full extent of exposure to cumulative perturbations and the net adaptive capacity available to respond to further disturbance. Like Smit and Pilifosova (2001), we have not specified the functional relationship between exposure and adaptive capacity; our aim is not to create a series of numerical indices, but to develop a better understanding of the links between vulnerability, exposure, and adaptive capacity. Our model implies a rate (or momentum) of change associated with vulnerability. This idea is borne out in the literature by the frequent reports of sequential impairment that erodes adaptive capacity to the point where a change (e.g., climate) can rapidly cause industrial or societal collapse (e.g., Jackson et al., 2001; Weiss and Bradley, 2001). We emphasize that vulnerability is inherently linked to dependence: once a community reaches its full ability to selforganize for provisioning within its surroundings, further growth leads to dependence on extrinsic and frequently economic components.

Figure 2 depicts linkages within an SES that lead to alternative provisioning practices, and Model 2 describes the attendant changes in vulnerability. We believe these concepts will be particularly useful at the local community scale to help us understand resilience or vulnerability of specific timescapes, focusing future research on causative processes that develop and interact across temporal and spatial scales to drive transitions in community provisioning. We will demonstrate how adaptive capacity has been fostered or lost within the four primary provisioning modes and how over-reliance on a single short-term opportunistic strategy has frequently led to collapse. In order to do this, we will look at adaptive elements that allowed persistence of a specific provisioning mode, or alternatively, sequential switching between modes. Furthermore, we will illustrate how communities that foster sharing networks mitigate many of the effects of change, thus promoting their resilience in a changing world. We diverge from the conventional application of adaptive management by calling for managers to recognize the value of past experience (e.g., social norms) and respond to the full temporal component of community adaptability, rather than simply fine-tuning short-term, yield-oriented resource quotas.

\section{SOCIAL-ECOLOGICAL TIMESCAPES}

\section{Hunting and Gathering}

The location of many Arctic communities in biophysically productive zones (here referred to as "hotspots") is primarily the result of two key facets of the northern ecosystem: 1) productivity is generally low and patchy, though some marine and coastal areas are highly productive (e.g., polynyas, see Henshaw, 2003); and 2) the migratory behavior of many Arctic species of mammal, birds, and fish may result in large aggregations moving between specific regions at predictable times and through specific locations. However, environmental conditions that fostered community development through hunting and gathering at these hotspots during one epoch may have precluded it during others, and may do so again in the future (e.g., muskoxen in Alaska; see Lent, 1999). Cultural conditions within indigenous communities may also have fostered natural resources at these hotspots through deliberate stewardship and practices (Beckerman and Valentine, 1996; Collings, 1997; Berkes and Folke, 2001; Freeman, 2001) or indirectly through creation of habitat mosaics (Smith and Wishnie, 2000; feedback in Fig. 2). Alternatively, cultural conditions, often as a result of changing technology, have at times allowed over-exploitation of species that are often long-lived and slow growing, with low reproductive rates (feedback in Fig. 2). This lack of synchrony between the biological/ecological timescape and human demand has led to examples of reduced ecological resilience and periodic localized extirpation of resources (e.g., Macpherson, 1981; Lent, 1999; Jackson et al., 2001). Human adaptation by switching to other harvestable resources or areas (if available) can mitigate loss of a focal 
prey resource and allow recolonization of that focal species; however, pulsed exploitation not only implies human adaptability (and sometimes also mobility) but also highlights the concurrent need for adaptability and mobility among the focal prey species (Lent, 1999). Cultures in specific timescapes may also redefine the term "resource" to suit changing demographic and ecological conditions. In the Canadian Arctic, with social parameters that have resulted in the decreased mobility of hunter/gatherer communities, norms that once favored consumption of resources such as marine mammals have expanded to include arctic cod and sculpins, foods that historically were used only for dogs and emergencies (Freeman, 2001).

Distinct eras of settlement and abandonment in the Arctic record are clear indications of these natural and anthropogenic impacts, as communities or industries either died out or departed in search of better living conditions, sometimes moving to areas that had been previously occupied and depleted, but had since recovered (Lent, 1999; CAFF, 2001). Historically, the penalties for failure to provide necessary resources from hunting and gathering were community demise and local transition of a SES to a modified ecological system. We argue that contemporary penalties, including community breakdown and abandonment, are functionally similar. In this respect, Arctic communities reliant on a pure hunting/gathering lifestyle may be regarded as "ecological hostages," dependent on local ecological conditions and therefore vulnerable to change. Although few Arctic communities could still be regarded as pure hunter/gatherers, protection of the natural capital associated with wildlife for subsistence continues to be vital to many communities. Subsistence hunting is important 1) for the economic benefit or necessity of consuming local foods, 2) for cultural needs, 3) for the nutritional value provided by locally derived foods (Freese, 2000), and 4) as a survival economy in periods of economic hardship (Ziker, 1999).

\section{Pastoralism}

Two prominent changes in Arctic resource provisioning can be described in relation to Rangifer tarandus (caribou or reindeer), which for millennia has been the most important terrestrial resource for Arctic peoples (Klein, 1996; Freese, 2000). In the 6th century AD on Russia's Yamal Peninsula, $R$. tarandus were domesticated for transport, facilitating substantial increases in a community's effective hunting range and resource options (CAFF, 2001) while reducing vulnerability to the vagaries of spatial or temporal migration patterns. Another revolution developed over the last 1000 years, as animal husbandry and oversight of greater numbers of $R$. tarandus marked the transition from a mode of subsistence based on hunting and gathering to a mixed economy based on hunting and gathering plus intensive, highly specialized, livestock pastoralism (Krupnik, 1993; Freese, 2000). Between 1700 and 1900, the domestic reindeer population rapidly increased across the Eurasian Arctic, and by the end of the 19 th century, wild reindeer hunting by many indigenous Eurasian cultures had virtually disappeared (Krupnik, 1993). Pastoral lifestyles may increase resilience of ecological systems through pulsed disturbances as herders move their animals to new pastures. However, several episodes of rapid decline of $R$. tarandus in areas of pastoralism across the Arctic have been attributed to changing biophysical conditions, irrespective of anthropogenic factors (Krupnik, 1993). The most dramatic repercussion of a pastoral lifestyle may be the three- to fourfold increase in ecological carrying capacity for humans that results from the transition between hunter/gather and pastoral lifestyles (Freese, 2000; CAFF, 2001). Furthermore, topdown government intervention in and control of reindeer pastoralism, via subsidies and other incentives, in Fennoscandia and Russia over the last century have led to pernicious socioeconomic and ecological effects (Paine, 1994). These effects have further stressed the environmental carrying capacity by delaying social ramifications, while allowing for continued aggravation of the underlying shortfalls of the biophysical environment to support community needs. In these cases, the lag effects of human population growth are out of synchrony with the regeneration of reindeer and their habitat, management responses, the balances between domesticated and wild $R$. tarandus, and social-ecological resilience (Fig. 1).

Increases in human populations as a result of pastoral lifestyles represent lifestyle dependence. Ecological deterioration as a result of elevated $R$. tarandus densities, mechanization, and social reorganization could preclude a return to a pure hunter/gatherer lifestyle during periods of changing pastoral fortunes, because of exceeding ecological carrying capacity thresholds and barriers to social adaptability.

\section{Agriculture}

Although agriculture has provided a technologically centralized solution to provisioning throughout human history, it can potentially raise human populations by orders of magnitude, leading to full-time craft specialization (Weiss and Bradley, 2001). In the circumpolar North, agriculture primarily includes the raising, grazing, and ranching of prey species (e.g., sheep and cows). Other forms of agriculture are less common in this harsh physical environment, but include forestry, aquaculture, grain, hay, and vegetables.

Scandinavian immigrants introduced agriculture to Iceland and Greenland during the last millennium. Although the Icelandic communities have survived to the present, those in Greenland disappeared sometime between 1350 and $1450 \mathrm{AD}$, when several factors, including cooling temperatures, precluded effective sheep farming. However, prior overgrazing by sheep was a key factor in progressively reducing the resilience of the farming system (CAFF, 2001). Apparently these agricultural 
communities did not have the social adaptability, or conversely held too rigid cultural commitments to certain patterns of hierarchy and purity (Langdon, 1995), to convert to a hunter/gatherer lifestyle. Concurrently, the timescape of the Thule culture continued through the perpetuation of hunting marine mammals on the sea ice. Currently, sheep herding has returned to southern Greenland, marking a recurrence of an agricultural timescape in this region. Only time will tell whether management will succeed in maintaining resilience and ensuring the sustainability of these agricultural endeavors while preventing another collapse. Conversion of local biomes for agriculture clearly comes at the risk of potential economic non-sustainability (Balmford et al., 2002) while increasing the human carrying capacity of the region. Greater incremental change to the environment leads to greater dependence on agriculture, and the greater the dependence on agriculture, the less opportunity for a subsistence survival economy in times of hardship. Remote communities may thus be left vulnerable to centralized decisions and subsidies to support their futures.

\section{Market-Based Economies}

We use the term "market-based economy" to represent a mode of living that, in its purest form, entails the purchasing of all products. Although trading, commerce, and assimilation of technologies between indigenous Arctic communities and Westerners has occurred for centuries, the latter part of the twentieth century, in part through globalization, brought a rapid increase in the influx of Western values (notably economic) and products to the region. This influx has been facilitated through Western policy, industrial developments from military installations, and endeavors such as mining and oil and gas development that brought new infrastructure, jobs, dividends, and local access to a Western lifestyle. However, full acceptance of market-based economies and access to technology by Arctic communities is a "tempting forbidden fruit" (Anderson, 2001:13) that can insidiously reconstitute the conditions of human existence. Continuing to incorporate global cultural values comes at the potential cost of progressive assimilation and dependence on the dominant society's institutional values (McBeath, 2001).

Although certain economic components from local industrial activities provide significant opportunities to some Arctic communities, their existence is often brief relative to the time taken for community development. The transition to a market-based economy during industrial activity (e.g., mining or oil and gas) may lead to different postactivity outcomes, depending on rate of effects. Figure 4 depicts the transition of a social-ecological system (SES) from hunting/gathering to a primarily market economy. Subsequent SESs may return primarily to hunting/gathering (including guiding and tourism; upper-right kite) or may be lost through disruption and lower resilience (lowerright kite). The return from a market-based economy to

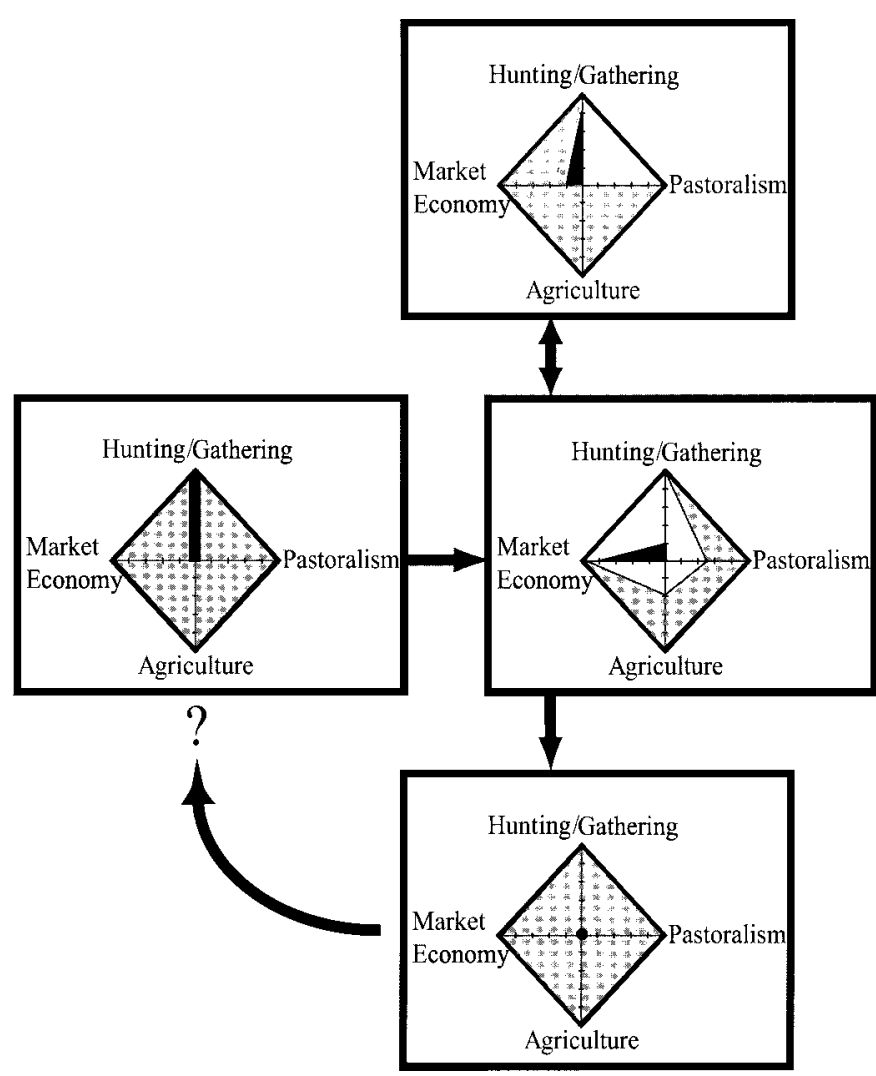

FIG. 4. SES transition from a hunting/gathering (left kite) to a primarily market economy (middle-right kite) and subsequent return to hunting/gathering (including guiding and tourism; upper-right kite) or loss through disruption and lowered resilience (lower-right kite). Grey shading illustrates hypothetical boundaries to adaptive capacity imposed by limits to technology (left kite), limits to the ability to fully partake in pastoralism or agriculture (middle-right kite), limits due to economics (upper-right kite), or ecological constraints (lower-right kite).

hunting/gathering with new technology may also not imperil resources because of the economic costs of acquiring, maintaining, and operating that technology (Chance, 1990).

A post-industrialized community that still encompasses a functioning ecosystem and adaptable social structure may survive as a part-economic entity through hunting and gathering of natural resources for economic returns. For example, consumptive use of wildlife through guided hunting and fishing trips or trapping is common (CAFF, 2001) and represents a timescape similar to a strict hunter/ gatherer lifestyle. Furthermore, meat from hunts is frequently left with guides and can supplement community needs. Ecotourism around wildlife in northern regions has also brought a rapid influx of people (Boo, 1990; CAFF, 2001) that can provide economic returns. However, the potential for ecotourism to disturb wildlife, people, and the physical environment may detract from the industry's overall benefits. In contrast, if the short-term industrial development that produces a market-based community economy concurrently reduces or destroys ecological resilience, the price can be the loss of the community when development abruptly ceases. Such loss is due to inherently reduced social resilience (loss of the ecological elements necessary for alternative provisioning practices). 
The "ecological footprint" (Wackernagel and Rees, 1997) of a community that moves to a market economy also grows substantially (even globally). Like pastoralism or agriculture, this larger "footprint" can raise the human carrying capacity (ecologically and economically) vastly above locally sustainable levels, resulting in a temporally dependent ecological deficit. The transition to economically driven provisioning may also lead to subjugated values and diminished cultural survival, further jeopardizing a return to a subsistence-type lifestyle if community economic fortunes are lost. This risk may be particularly pertinent to communities with no tradition of harvest limitations for certain species (e.g., for those where full utilization of available resources has been a social imperative; e.g., Meltofte, 2001). Finally, recognizing that the trade-offs from a Western lifestyle are frequently borne by minorities and peripheral communities (Gottlieb, 1993) illuminates the ironic price of eating the "forbidden fruit" in an environment already suffering from Western industrial environmental degradation. The result of contaminated resources or a rapidly changed environment can only push communities further down the avenue of economic dependence and potential assimilation.

\section{CASE STUDIES}

The above descriptions of the four primary provisioning methods in the circumpolar North illustrate the dependencies associated with each mode of provisioning. Overreliance on any single provisioning method, whether internally or externally motivated, has the potential to reduce resilience in times of change, particularly today when moving communities is economically and institutionally difficult. The case studies below illustrate strategies that have fostered community resilience during periods of a) changes in a mixed harvest/market economy and b) loss of market-based economy.

\section{Adaptation to Change in a Mixed Harvest/Market Economy}

Magdanz et al. (2002) reported on the social organization of the production and distribution of wild food for subsistence in Wales and Deering, two Iñupiaq Eskimo communities in northwest Alaska. Both communities are remote settlements on sites with long histories and dependable access to wild animals, fish, and plants. A wide diversity of animal species are harvested: 64 by Wales residents and 69 by Deering residents. As in other remote, resource-dependent communities in Alaska, about $30 \%$ of the households accounted for $70 \%$ or more of the harvest by weight. Both communities have at least partially integrated into the market economy, with three-quarters of their personal income originating from public sector wages and transfer payments and the other quarter heavily dependent on public spending. The result is that the communities are no longer fully self-sufficient, depending to some extent on imported goods.
Both Wales and Deering use extended-family networks to optimize most of their wild food production and distribution in ways that are efficient, culturally appropriate, and personally satisfying (Magdanz et al., 2002). However, that freedom is due to their remote locations and not the result of informed management by government agencies, whose regulations favor individuals and households but disadvantage extended-family networks. In times of shortage, government agencies have tended to adopt regulations that reorganized subsistence production and distribution, disrupted family networks, and reduced subsistence efficiency, but may not have reduced actual harvests. Centralized management such as this that favors regional individuals, rather than local extended-family subsistence networks, can clearly lead to greater harvests while depleting the long-term opportunities of remote communities to survive.

Family networks have facilitated the optimization of effort and high degrees of individual freedom. However, and perhaps most importantly, they have provided some degree of security against pervasive and unpredictable social, ecological, and economic changes. Illustrations of this are cases of misfortune for Wales and Deering families that stepped away from the local system of networks. When key jobs evaporated or businesses failed, family units that embraced Western cultural integration and local economic development sometimes failed to survive in these communities. Conversely, community members that fully participated in local family networks appeared to be better prepared to survive life in Alaska. "A household without employment can depend on other households for food, equipment, and supplies. When hunting is poor, every household in a network benefits from the success of even a single hunter in the network" (Magdanz et al., 2002:123). We interpret the normative behavior associated with such extended-family networks as an evolved mitigation of uncertainty. The diversity within a local family network fosters adaptation to new conditions and challenges as they arise, whether they are social, ecological, economic, or combinations of all three. Furthermore, these networks implicitly recognize the temporal nature of provisioning - the evolved normative behavior favoring the benefits of long-term sharing over individual, shortterm boom and bust.

\section{Loss of Market-Based Economy}

Wales and Deering provide examples of communal sharing to mitigate uncertainty and change in social, ecological, or economic aspects of resource provisioning. However, profound changes elsewhere in the circumpolar North have forced entire communities, rather than individuals, families, or networks, to adapt to profound regressions in community development. Reverting from a mixed harvest/market-based economy to primarily harvesting has been termed a "survival economy" (Ziker, 1999). An example is the response of local communities in the 
$850000 \mathrm{~km}^{2}$ Taimyr Autonomous Region in Russia to the collapse of socialism.

Beginning in the 1930s, rural native populations in the Taimyr region were incorporated into the Soviet agroindustrial complex. Large-scale harvesting of wildlife by local workers to supply neighboring industrial complexes led to relatively high standards of living throughout the 1980s. Men, women, and children (through education) all benefited from the rewards of economic and cultural development. Cash purchasing of goods was the norm prior to 1991. However, after the collapse of socialism, cash became only a supplement. Furthermore, capital investments in the local lands during the socialist period tended to revert back to communal use. Kinship cooperation in production, non-market distribution, sharing networks, and communal consumption have all been used to ensure local community survival. The key components of the survival economy are decreased external inputs and dependencies (Ziker, 1999). This case study illustrates that extended social norms that allowed for a tribal network of sharing and cooperation benefited the community's resilience during this profound economic change.

Ziker (1999) explores why the decline in the market economy did not lead to an exodus to local urban centers and concludes that it is a matter of risk. He showed that the subsistence economy is relatively predictable for provisioning as compared to the market economy, and particularly so given the rural community's relatively short exposure to the latter. Economic fortunes for all remote, resource-dependent communities are likely to be sporadic; therefore, maintaining the critical norms necessary to operate within a survival mode at times when resources (particularly those associated with a cash economy) are sparse appears to be a valuable evolved component of resilience.

\section{APPLICABILITY OF TIMESCAPE MODELS TO FUTURE MANAGEMENT}

The future states of the Arctic SESs are increasingly difficult to predict. This difficulty is frequently a consequence of modernity and the advent of social institutions in nation-states that have circumscribed the lives of indigenous peoples (Berardi, 1998; Nuttall and Callaghan, 2000). Changes in both biophysical factors (e.g., climate and contaminants; see Weiss and Bradley, 2001; Krupnik and Jolly, 2002) and socio-cultural factors (e.g., population growth, cultural assimilation, media, and transportation) produce acute conditions of uncertainty, volatility, and transition. However, we argue that in the Arctic, environmental perceptions are conserved primarily because of the comparatively small response margins. Thus, by understanding the human perceptions, and range of socially and culturally acceptable responses to change in specific timescapes, we will better be able to predict future vulnerabilities, even if redistributions of biophysical factors

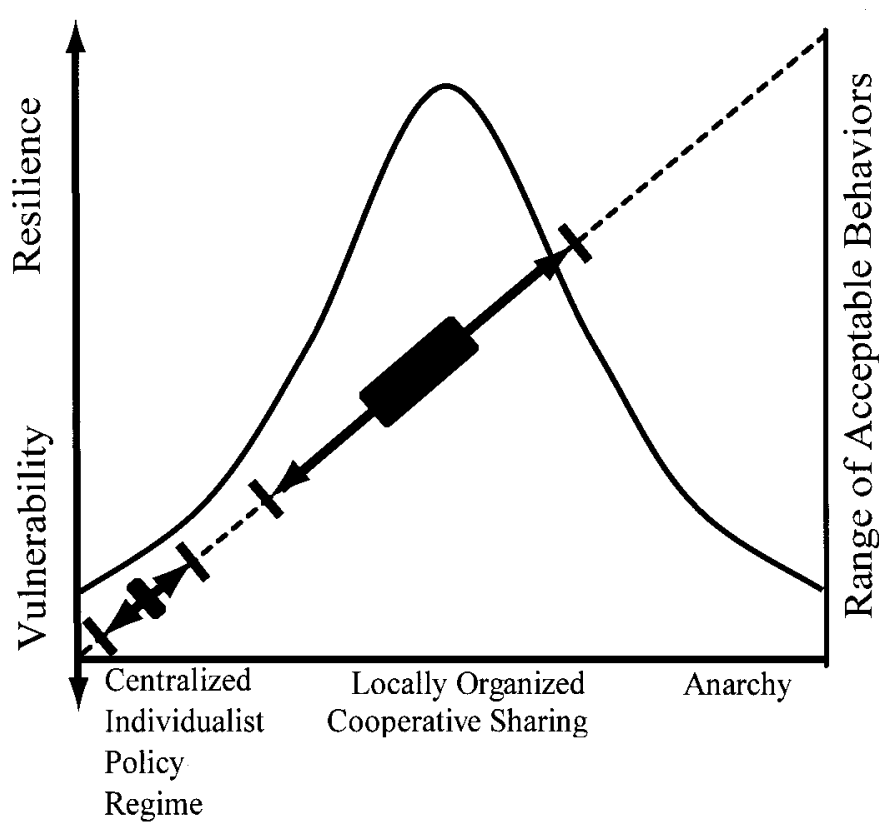

Social-Ecological Relationship

FIG. 5. Conceptual representation of social-ecological resilience and community organization. Solid curve shows resilience or vulnerability of each community type, and dotted line shows the range of normative behaviors associated with a community's social-ecological relationship. Black rectangles indicate current social norms for centralized and local-cooperative community regimes. These norms are dynamic and operate within a range of historical experience (arrowed line with end-bars)

such as climate are difficult to predict. Orr's (2002) conclusions that we are globally heading into a downward cycle that will result in lower social complexity (Tainter, 1990) and a lesser economy based on renewable resources (Odum and Odum, 2001) also suggest that past system configurations may be more likely to return than globalization (itself a repeating timescape; Seijo et al., 2001) and technology might imply. Furthermore, most of the world's population will continue to be subsistence or small-scale market agriculturalists (Weiss and Bradley, 2001) and habitat tracking as an adaptive response in a crowded world will not be possible. Therefore, maintaining or maximizing options for alternative provisioning, or at least a survival economy, will be vital to remote communities wishing to maintain their long-term resilience, irrespective of their ability to acquire food and shelter by economic means. Figure 5 shows the conceptual relationship between social-ecological resilience or vulnerability and community organization. We hypothesize that resilience is positively correlated with locally organized adaptive communal strategies and negatively correlated to centralized, individual-favoring policies and to the lack of cohesion associated with anarchy. Resilience might be regarded as the social adaptive capacity that encompasses intergenerational memory, dormant institutions, and embedded normative behavior. We expect that social norms will be broader in marginal than in temperate environments. Mitigation of long-term risk, vulnerability, and intergenerational injustice in locally organized cooperative 
sharing communities is achieved through norms that allow a diversity of provisioning and survival options, rather than relying on the frequent centralized Western policy response of subsidizing unsustainable and resiliencedepleting practices. We support the view that effective policy is founded on processes that favor the ability of communities to respond to disturbances and provide the means to offset those disturbances (Glantz, 1991; Kelly and Adger, 2000). Resilience, in this view, becomes a function of the architecture of a specific SES timescape and the concurrent ability of communities to fulfill needs and realistic desires under an inevitably wide array of social, ecological, or economic conditions-and not just those currently manifested.

Fundamental social, cultural, cognitive, and feedback differences separate the four primary provisioning practices we describe. Although the development of pastoralism, agriculture, and access to a market economy have increased the array of options for Arctic communities that were originally hunter/ gatherers to acquire resources, each practice comes with temporally diverse tradeoffs and sunk-cost risks (Janssen et al., 2003) as a result of feedbacks with the biophysical and cultural environments. The hunter/gatherer lifestyle relies strictly on predation or gathering of wild stocks and places humans in direct competition with other predators or consumers. In this environment, both harvest resources and the physical environment are communal assets, and wealth is divided relatively evenly. Pastoralism restricts access to the prey, at both human and individual levels (animals represent wealth), but in a still communal physical environment. Agriculture represents further restrictions, since both prey and the restricted physical environment in which they are kept are privately owned, and wealth becomes a powerful and localized commodity (Ingold, 1980). Finally, a market-based economy represents use of products that are often external to the immediate ecological environment, which are valued for their scarcity and require wealth to import them. The relative importance of economic wealth in the different modalities is critical, in that it doesn't reflect social-ecological wealth (e.g., critical natural capital; Deutsch et al., 2003), which incorporates the concept of community resilience. In this respect, a transition from a pure hunter/gatherer lifestyle to a pure market-based economy in the long term is not just a provisioning choice, but a shift in cultural trajectory. The lifestyles might be regarded as a continuum from "ecological hostage" to "economic hostage."

The challenge for Arctic communities is to maintain their long-term viability, socially, economically, and culturally, despite the unpredictability of future conditions, by promoting resilience and sustainable harvest of local resources. Furthermore, the resilience of Arctic communities is challenged by nation-states that inhibit locally specific, long-term resource availability around communities and the entitlement of individuals and groups to access these resources. Social-ecological resilience will be fostered only through recognition of reasonable longterm objectives. Western evidence suggests that once a minimal level of subsistence is achieved, an increase in a community's overall level of consumption will have no effect on the average well-being of individuals in that community; an individual's subjective well-being depends not on absolute personal wealth, but on wealth relative to the average in society (McBride, 2001). Therefore, the relatively short-term (decades rather than centuries) opportunities (frequently associated with extraction industries) that can unsustainably raise human and economic capacities within a finite biophysical system should be carefully monitored if functional post-development system states are desired. We expect that consumptive and non-consumptive use of wild species will be fundamental to the future survival of many Arctic communities, to supply either food, clothing, materials, trade, guided hunting and fishing, or culturally important values.

Traditional ecological knowledge (Huntington, 2000) gleaned from tribal and community elders through collection of diachronic information indicates an astute awareness that the small, incremental changes that are taking place are indicators of potential long-term and major problems in the future (Legat, 2001). We expect that survival of Arctic communities has depended, and will continue to depend, on a long-term perspective that encompasses effective responses to these small, incremental changes as well as maintenance (protection) of critical social, ecological, and economic components necessary for system function. Accordingly, actions that promote resilience by mitigating gradual changes, rather than crisis management of the effects of profound disturbances (Scheffer et al., 2001), might be successful. Wise management should be the result of a process that recognizes the evolved experience embedded in social and cultural norms. For example, the survival of extended family networks in Alaska and the Taimyr region is testament to their importance, efficiency, and effectiveness in producing and distributing wild foods to families (Magdanz et al., 2002). For communities in which normative behavior encompasses a diversity of components for reorganization, equity, and sharing, resilience in the face of profound change appears to be much greater than it is for those communities with policies focused on individuals. Communal sharing (of provisioning and risk) as a sustainable response, rather than inequitable resource distribution, addresses the four priorities identified by Kelly and Adger (2000:325) that improve the situation for the most vulnerable members of communities: "poverty reduction; risk-spreading through income diversification; respecting common property management rights; and promoting collective security." Furthermore, recognition that some traditional practices may be similar, or have parallels, to complex systems theoryemphasizing nonlinear relationships, threshold effects, multiple equilibria, existence of several stability domains, cross-scale linkages in time and space, disturbance and surprise (Berkes and Folke, 2001) — has profound relevance to continued community stewardship of local social-ecological systems. We believe that collaboration between 
communities and scientists to understand social-ecological timescapes of resource use will elucidate answers to the significant challenge of maintaining equity and resilience within the Arctic and provide coping strategies in times of change. It will also help identify fundamental flaws in existing relationships between Western culture, economics, and the environment that currently may impede the ability of communities to be self-sustaining.

\section{ACKNOWLEDGEMENTS}

This paper is a product of the University of Alaska, Anchorage (UAA) Resilience and Adaptive Management (RAM) Group. We thank the Human Dimensions of the Arctic System (HARC) program of the National Science Foundation for generating the impetus to write this manuscript; the staff of the Alaska Resources Library (ARLIS) for help in collecting published information; and Amy Lewis, Fae Korsmo, Kyle Joly, and David Natcher for detailed and helpful editorial comments. We also thank Fikret Berkes for spirited discussion on the conceptual content.

\section{REFERENCES}

ADAM, B. 1998. Timescapes of modernity: The environment and invisible hazards. London: Routledge. 250 p.

ANDERSEN, T., KRUSE, J., and POPPEL, B. 2002. Survey of living conditions in the Arctic: Inuit, Saami and the indigenous peoples of Chukotka (SLICA). Arctic 55(3):310-315.

ANDERSON, J. 2001. Northern communities and the state: Is resistance "futile?" The Northern Review 23:9-16.

BALMFORD, A., BRUNER, A., COOPER, P., COSTANZA, R., FARBER, S., GREEN, R.E., JENKINS, M., JEFFERISS, P., JASSAMY, V., MADDEN, J., MUNRO, K., MYERS, N., NAEEM, S., PAAVOLA, J., RAYMENT, M., ROSENDO, S., ROUGHGARDEN, J., TRUMER, K., and TURNER, R.K. 2002. Economic reasons for conserving wild nature. Science 297:950-953.

BECKERMAN, S., and VALENTINE, P. 1996. On Native American conservation and the tragedy of the commons. Current Anthropology 37(4):659-661.

BECKLEY, T., PARKINS, J., and STEDMAN, R. 2002. Indicators of forest-dependent community sustainability: The evolution of research. The Forestry Chronicle 78(5):626-636.

BERARDI, G. 1998. Natural resource policy, unforgiving geographies, and persistent poverty in Alaska Native villages. Natural Resources Journal 38:85-108.

BERKES, F., and FOLKE, C. 2001. Back to the future: Ecosystem dynamics and local knowledge. In: Gunderson, L.H., and Holling, C.S. Panarchy: Understanding transformations in human and natural systems. Washington, D.C.: Island Press. 121-146.

BOO, E. 1990. Ecotourism: The potentials and pitfalls. Washington, D.C.: Wickersham Printing Company, Inc. 246 p.

CAFF (CONSERVATION OF ARCTIC FLORA AND FAUNA). 2001. Arctic flora and fauna: An introduction to biodiversity, status, and conservation. Helsinki: Edita. 272 p.
CARPENTER, S.R., and GUNDERSON, L.H. 2001. Coping with collapse: Ecological and social dynamics in ecosystem management. BioScience 51:451-457.

CARPENTER, S., WALKER, B., ANDERIES, J.M., and ABEL, N. 2001. From metaphor to measurement: Resilience of what to what? Ecosystems 4:765-781.

CHANCE, N.A. 1990. The Iñupiat and Arctic Alaska: An ethnography of development. Fort Worth, Texas: Holt, Rinehart and Winston, Inc. $241 \mathrm{p}$.

COLLINGS, P. 1997. The cultural context of wildlife management in the Canadian North. In: Smith, E.A., and McCarter, J., eds. Contested Arctic: Indigenous peoples, industrial states, and the circumpolar environment. Seattle: University of Washington Press. 13-40.

COSTANZA, R. 1996. Ecological economics: Reintegrating the study of humans and nature. Ecological Applications 6(4): 978-990.

DEUTSCH, L., FOLKE, C., and SKÅNBERG, K. 2003. The critical natural capital of ecosystem performance as insurance for human well-being. Ecological Economics 44:205-217.

FOLKE, C., CARPENTER, S., ELMQVIST, T., GUNDERSON, L., HOLLING, C.S., WALKER, B., BENGTSSON, J., BERKES, F., COLDING, J., DANELL, K., FALKENMARK, M., GORDON, L., KASPERSSON, R., KAUTSKY, N., KINZIG, A., and LEVIN, S.A. 2002. Resilience and sustainable development: Building adaptive capacity in a world of transformations. Report for the Swedish Environmental Advisory Council 2002:1. Stockholm: Ministry of the Environment.

FREEMAN, M.M.R. 2001. Small-scale whaling in North America. In: McGoodwin, J.R., ed. Understanding the cultures of fishing communities. A key to fisheries management and food security. FAO Fisheries Technical Paper No. 401. 169-194.

FREESE, C.H. 2000. The consumptive use of wild species in the Arctic: Challenges and opportunities for ecological sustainability. Report to WWF Canada and WWF International Arctic Programme. http://wwf.ca/NewsAndFacts/Supplemental/ ConsumptiveUseOfWildSpecies.pdf.

GLANTZ, M.H. 1991. The use of analogies in forecasting societal responses to global warming. Environment 33:10-15, 27-33.

GOLDMAN, M., and SCHURMAN, R.A. 2000. Closing the "great divide": New social theory on society and nature. Annual Review of Sociology 26:563-584.

GOTTLIEB, R. 1993. Ethnicity as a factor: The quest for environmental justice. In: Gottlieb, R., ed. Forcing the spring: The transformation of the American environmental movement. Washington D.C.: Island Press. 235-269.

HAILA, Y. 1999. Biodiversity and the divide between culture and nature. Biodiversity and Conservation 8:165-181.

HENSHAW, A. 2003. Polynyas and ice edge habitats in cultural context: Archaeological perspectives from southeast Baffin Island. Arctic 56(1):1-13.

HOLLING, C.S. 1986. Resilience of ecosystems: Local surprise and global change. In: Clark, W.C., and Munn, R.E., eds. Sustainable development of the biosphere. Cambridge: Cambridge University Press. 292-317.

. 2001. Understanding the complexity of economic, ecological, and social systems. Ecosystems 4:390-405. 
HOLLING, C.S., and MEFFE, G.K. 1996. Command and control and the pathology of natural resource management. Conservation Biology 10:328-337.

HUNTINGTON, H.P. 2000. Using traditional ecological knowledge in science: Methods and applications. Ecological Applications 10(5):1270-1274.

INGOLD, T. 1980. Hunters, pastoralists, and ranchers: Reindeer economics and their transformations. Cambridge: Cambridge University Press. 296 p.

JACKSON, J.B.C., KIRBY, M.X., BERGER, W.H., BJORNDAL, K.A., BOTSFORD, L.W., BOURQUE, B.J., BRADBURY, R.H., COOKE, R., EARLANDSON, J., ESTES, J.A., HUGHES, T.P., KIDWELL, S., LANGE, C.B., LENIHAN, H.S., PANDOLFI, J.M., PETERSON, C.H., STENECK, R.S., TEGNER, M.J., and WARNER, R.R. 2001. Historical overfishing and the recent collapse of coastal ecosystems. Science 293:629-638.

JANSSEN, M.A., KOHLER, T.A., and SCHEFFER, M. 2003. Sunk-cost effects and vulnerability to collapse in ancient societies. Current Anthropology 44(5):722-728.

KELLY, P.M., and ADGER, W.N. 2000. Theory and practice in assessing vulnerability to climate change and facilitating adaptation. Climatic Change 47:325-352.

KLEIN, D.R. 1996. Structures for caribou management and their status in the circumpolar north. Rangifer, Special Issue 9:245-252.

KRUPNIK, I. 1993. Arctic adaptations: Native whalers and reindeer herders of northern Eurasia. Hanover, New Hampshire: University Press of New England.

KRUPNIK, I., and JOLLY, D. 2002. The earth is fasternow: Indigenous observations of Arctic environmental change. Fairbanks, Alaska: Arctic Research Consortium of the United States. 384 p.

LANGDON, S.J. 1995. Increments, ranges, and thresholds: Human population responses to climate change in northern Alaska. In: Peterson, D.L., and Johnson, D.R., eds. Human ecology and climate change: People and resources of the Far North. Washington, D.C.: Taylor \& Francis Publishing. 139-154.

LEGAT, A. 2001. Showing respect for caribou. In: Arctic flora and fauna: An introduction to biodiversity, status, and conservation. Helsinki: Edita. 69.

LENT, P.C. 1999. Muskoxen and their hunters. Norman: University of Oklahoma Press.

MACPHERSON, A.H. 1981. Commentary: Wildlife conservation and Canada's North. Arctic 34:103-107.

MAGDANZ, J.S., UTERMOHLE, C.J., and WOLFE, R.J. 2002. The production and distribution of wild food in Wales and Deering, Alaska. Technical Paper 259. Juneau: Division of Subsistence, Alaska Department of Fish and Game.

McBEATH, G.A. 2001. Changing capabilities of northern communities: Environmental protection. The Northern Review 23:164-179.

McBRIDE, M. 2001. Relative-income effects on subjective wellbeing in the cross-section. Journal of Economic Behavior and Organization 45:251-278.

McGOODWIN, J.R. 1990. Crisis in the world's fisheries: People, problems, and policies. Palo Alto, California: Stanford University Press.

McTIERNAN, T. 1999. Northern communities and sustainable development in Canada's North. In: Pierce, J.T., and Dale, A., eds. Communities, development and sustainability across Canada. Vancouver: UBC Press. 90-120.

MELTOFTE, H. 2001. Unsustainable take of murres in Greenland. In: Arctic flora and fauna: An introduction to biodiversity, status, and conservation. Helsinki: Edita. 88-89.

NAKASHIMA, D., PROTT, L., and BRIDGEWATER, P. 2000. Tapping into the world's wisdom. UNESCO Sources 125(JulyAugust):12.

NEWTON, S.T., FAST, H., and HENLEY, T. 2002. Sustainable development for Canada's Arctic and Subarctic communities: A backcasting approach to Churchill, Manitoba. Arctic 55(3): $281-290$.

NUTTALL, M., and CALlaGHAN, T.V. 2000. The Arctic: Environment, people, policy. Amsterdam: Harwood Academic Publishers.

ODUM, H.T., and ODUM, E.C. 2001. A prosperous way down: Principles and policies. Boulder: University Press of Colorado.

ORR, D. 2002. Four challenges of sustainability. Conservation Biology 16(6):1457-1460.

PAINE, R. 1994. Herds of the tundra: A portrait of Saami reindeer pastoralism. Washington, D.C.: Smithsonian Institution Press.

SCHEFFER, M., CARPENTER, S., FOLEY, J.A., FOLKES, C., and WALKER, B. 2001. Catastrophic shifts in ecosystems. Nature 413(11 October):591-596.

SCHLOSSER, P., WALSH, J., WARNICK, W., and YORK, A. 1998. Opportunities in Arctic Research: Final Report. Fairbanks, Alaska: Arctic Research Consortium of the United States.

SEIJO, G., OSWICK, C., and KEENOY, T. 2001. Timescapes of globalization: Old times in new times? Short position paper presented at the International Conference on Spacing and Timing: Rethinking Globalization and Standardization, 1-3 November 2001, Palermo, Italy.

SMIT, B., and PILIFOSOVA, O. 2001. Adaptation to climate change in the context of sustainable development and equity. In: McCarthy, J.J., Canzianni, O.F., Leary, N.A., Dokken, D.J., and White, K.S., eds. Climate Change 2001: Impacts, adaptation, and vulnerability: Contribution of Working Group II to the Third Assessment Report of the Intergovernmental Panel on Climate Change. Cambridge: Cambridge University Press.

SMITH, E.A., and WISHNIE, M. 2000. Conservation and subsistence in small-scale societies. Annual Review of Anthropology 29:493-524.

STOFFLE, R.W. 2001. When fish is water: Food security and fish in a coastal community in the Dominican Republic. In: McGoodwin, J.R., ed. Understanding the cultures of fishing communities: A key to fisheries management and food security. FAO Fisheries Technical Paper No. 401. 219-245.

TAINTER, J. 1990. The collapse of complex societies. Cambridge: Cambridge University Press.

WACKERNAGEL, M., and REES, W.E. 1997. Perpetual and structural barriers to investing in natural capital: Economics from an ecological footprint perspective. Ecological Economics $20: 3-24$.

WALKER, B., CARPENTER, S., ANDERIES, J., ABEL, N., CUMMING, G.S., JANSSEN, M., LEBEL, L., NORBERG, J., PETERSON, G.G., and PRITCHARD, R. 2002. Resilience management in social-ecological systems: A working hypothesis 
for a participatory approach. Conservation Ecology 6(1). http:/ /www.consecol.org/vol6/iss1/art14

WCED (WORLD COMMISSION ON ENVIRONMENT AND DEVELOPMENT). 1987. Our common future. Oxford: Oxford University Press.

WEISS, H., and BRADLEY, S. 2001. What drives societal collapse? Science 291(26 January): 609-610.
YOUNG, O.R. 1992. Arctic politics: Conflict and cooperation in the circumpolar north. Hanover, New Hampshire: University Press of New England.

ZIKER, J.P. 1999. Survival economy and core-periphery dynamics in the Taimyr autonomous region. Russia. Anthropology of Eastern Europe Review 17(2):59-65. 